\title{
Species Richness Capture Plant Functional and Phylogenetic Diversity Variations Along Different Ecosystems on the Hillsides of Damavand Mountain (Iran)
}

majid sadeghinia

Ardakan University

Bahram gholinejad

university of Kurdistan

Mansoureh kargar ( $\nabla$ kargar_sahar@yahoo.com )

Sari Agricultural Sciences and Natural Resources University

\section{Research Article}

Keywords: community weighted means. Functional richness. Grassland.LHS scheme. Mean pairwise dissimilarities. Plants traits. Shrubland; Soil nutrients

Posted Date: July 13th, 2021

DOI: https://doi.org/10.21203/rs.3.rs-673779/v1

License: (c) (1) This work is licensed under a Creative Commons Attribution 4.0 International License.

Read Full License 


\section{Abstract}

Aims Plants vary in their functional traits and thus in their preference towards edaphic conditions. Plants displaying tougher, long-living leaves, which better conserve nutrients in the tissues, are expected to grow better in acidic soils, which are frequently nutrient poor.

Methods We used a trait-based approach, quantifying variations in the Leaf-height-seed (LHS) scheme and functional and phylogenetic indices in semi-arid communities from three different habitats (grasslands, shrubland and mixed habitats). Three traits, including specific leaf area (SLA), Plant height $(\mathrm{H})$ and Seed Mass (SM), in 350 plots across the three habitats in the southern hillsides of Damavand Mountain. We only included the species that occurred in more than 20 plots throughout the dataset for the following analyses (i.e., 44 species). We calculated at the plot scale, community weighted means (CWM) for each trait, species richness, Faith's phylogenetic diversity index (PD), functional richness (Frich), functional and phylogenetic mean pairwise dissimilarities (MPD) and nutrient concentration.

Results The results showed that the higher soil nutrient concentration and $\mathrm{pH}$ were significant and positive related with species and functional richness and Faith's phylogenetic distance, while not significant results were obtained for any functional trait at community level (SLACWM, VHCWM and SMCWM) or for the functional and phylogenetic mean pairwise distance.

Conclusiones In addition, the phylogenetic and functional patterns responded more to the taxonomic richness variations than to trait-based assembly processes.

\section{Introduction}

The importance of soil and vegetation management to achieve the United Nations Goals for sustainability (Keesstra et al. 2016) has been highlighted in the last decade due to the central role that both elements play in ecosystem services. Plant-soil interactions provide mechanistic information on the ecosystem's adaptation to the environment (Berdugo et al. 2017), especially in drylands in montane ecosystems, where the soil resources and land use are key factors that explain vegetation structure evolution (Eldridge et al., 2016; Salgado-Luarte et al. 2019; Vaieretti et al. 2018). In this regard, the functional trait-based approach has emerged as a powerful tool to evaluate the evolutionary history and adaptations of plants to a wide range of abiotic factors (Lavorel and Garnier. 2002; Jafarian et al. 2019). In addition, many studies have provided information on the potential impact of the global change on vegetation using functional trait analysis of plant communities along environmental gradients across different biomes (e.g. Pérez-Ramos et al. 2012; Junk et al. 2014) or at global scale (e.g. Yang et al., 2015; Wieczynski et al., 2018). However, notwithstanding the relevant information obtained by these studies, additional empirical information on functional train variation in plant communities is needed to accurately infer their sensitivity to ongoing global change (Pérez-Ramos et al., 2017).

Arid and semi-arid regions will be among the areas on the planet most affected by global change (Delgado-Baquerizo et al. 2013). However, the current knowledge of the effects of global change on plant 
communities has been biased to certain regions of the planet (e.g. Mediterranean-climate regions; LeónSánchez et al. 2020; Pérez-Ramos et al. 2017; Sardans et al. 2011), while others, such as western Asia, have been generally overlook (but see Bergholz et al. 2017). In Iran, rangelands occupy nearly $54.6 \%$ of the landscape with high plant diversity due to its climate conditions. However, human activities (e.g. land use and climate change) and the lack of a proper environmental policy are responsible of the shifts in the ecosystem properties of the rangelands from Iran. For instance, recent studies from Iran have shown that global change caused a shift in vegetation composition and soil biogeochemical cycles (Ashrafzadh and Erfanzadeh. 2014). But, the impact from a functional and phylogenetic point of view has been largely ignored (Jafarian et al. 2019).

Given that plants all use the same types of resources (e.g. nutrients and water), the resource uptake traits may be a way to more accurately discriminate between species with regard to ecological strategies. For instance, the leaf economics spectrum (LES, Wright et al. 2004) represents the trade-off between acquisition and conservation of resources, being the specific leaf area (SLA; light-capturing area deployed per dry mass allocated) one of the best predictors of the LES (Wright et al. 2004). However, the leading dimensions of ecological variation among plants include not only traits related with resource uptake but also those associated with competition for light and reproductive ability (Díaz et al. 2016). To this end, Westoby (1998) proposed the leaf-height-seed (LHS) strategy scheme, which captures the strategy of plants by three trait-related independent dimensions of ecological variation. Hence, the LHS scheme assumes that leaf economics is essentially independent of the dimensions of plant height and seed production (Laughlin et al.2010).

Moreover, the community assembly patterns cannot be assessed by a single measure of functional composition (i.e. the dominant trait values expressed by the community weighted means; Garnier et al. 2004) but rather needs a multi-faceted approach (de Bello et al., 2013). Other descriptors of functional and phylogenetic structure may allow inferring relevant processes and can help predict community responses to global change (Salgado-Luarte et al., 2019; Chang et al., 2019). Investigating the functional and phylogenetic structure of communities can thus provide useful insight to understand the outcome of both environmental and historical factors involved in the species assembly. Thus, while the phylogenetic structure provides tools to explore the role of the different evolutionary histories of the species in the community assembly, the functional structure is closely related to the different ecological strategies used to cope with environmental filters (Tanaka and Sato, 2015; Xu et al., 2017). For instance, phylogenetic and/or functional over dispersion can occur among communities situated in similar habitats as a direct consequence of competitive exclusion between similar species, while strong abiotic filtering may promote phylogenetic and/or functional clustering by the selection of certain traits or clades imposed by the environmental constraints (Cavender-Bares et al. 2009; Xu et al. 2017).

In this study, we test the relationship between the simple traits of the LHS model and quantify the variation of the functional and phylogenetic indices of plant communities along natural resource gradient in the southern hillsides of Damavand Mountain. To this end, we have measured the species richness and several metrics of the functional and phylogenetic structure in 350 plots from three different habitats 
associated with different intensity of grazing (grasslands, shrubland and mixed habitats) and nutrient concentration. At the community level, the LHS model seems to represent most of the variation in species composition in a grazing context (Golodets et al. 2009): heavy grazing could favor higher rates of resource capture from the environment to support high growth rates (high SLA) and shorter plants with large seeds, which favors seedling establishment in the disturbed environment (Cingolani et al. 2005; Golodets et al. 2009). Grazing might also increase the functional or phylogenetic redundancy by filtering out species that lack traits, such as low stature and/or seed mass, to persist under grazing disturbance (de Bello et al. 2006). Alternatively, higher resource availability may enhance the establishment of species having traits associated with higher growth rate and competition (higher SLA and plant height), which could promote higher functional and phylogenetic dissimilarity between dominant species (de Bello et al., 2013; de la Riva et al. 2019). We tested these predictions: firstly, by examining the responses of the functional LHS trait composition at community level between habitats along the soil nutrient gradient; secondly, by comparing the species richness and the functional and phylogenetic diversity indices with the above mentioned factors.

\section{Materials And Methods}

Study site

Of the total land area of Iran, about $52.4 \%$ are rangelands; $8.6 \%$ are forests and $19.5 \%$ are deserts including bare salty lands. There are three main climatic zones in Iran, including arid and semi-arid regions of the interior and far south, Mediterranean climate (mainly in the western Zagros Mountains, the high plateau of Azerbaijan, and the Alborz mountains) and humid and semi-humid regions (mainly in the Caspian, but also in west Azerbaijan and the southwest Zagros). The study area is located in plant geography zone of Europe - Siberia (the Hyrcanian area). The study area, the southern hillsides of Damavand Mountain, is located in the North part of Iran $\left(52^{\circ} 11^{\prime}-52^{\circ} 5^{\prime} \mathrm{N} ; 35^{\circ} 46^{\prime}-35^{\circ} 49^{\prime} \mathrm{E}\right)$. It covers ca. 6000 ha and has an elevation stretching from $2500 \mathrm{~m}$ asl to $34600 \mathrm{~m}$ asl. The climate is semi-arid cold. Minimum monthly mean $-0.3^{\circ} \mathrm{C}$ and Maximum monthly mean $19.2^{\circ} \mathrm{C}$. The mean annual temperature of $12.7^{\circ} \mathrm{C}$; and the mean annual precipitation of $652 \mathrm{~mm}$. The climatic varibales were computed from the mean annual precipitation, mean annual moisture and mean annual temperature data recorded for the period $1985-2010$ by the Rineh network of meteorological stations $\left(35^{\circ} 54^{\prime} ; 52^{\circ} 04^{\prime} \mathrm{E}\right)$ (Fig. 1). The soil type of the study area is sandy-loamy and silty soil. The bedrock is primarily calcareous. The soils are variable, ranging from deep brown soils to shallow lithological soils, the latter exerting a greater influence on vegetation. Basic cations and carbonates promote an alkaline pedogenesis that can be followed by an acidic pedogenesis after carbonate lixiviation.

\section{Experimental design}

The experiment was carried out in three different habitats: grassland, dominated by Agropyron repens, Festuca ovina, Bromus tectorum and Bromus tomentellus, shrubland, dominated by Artemisia aucheri, Astragalous aegobromus, Eringium billardeieri and Thymus kotschyanus, and a transitional fringe 
between both habitats, which we called "mixed area", dominated by Astragalus ochrodeucus, Festuca ovina, Onobrychis cornuta and Bromus tomentellus. These habitats are adjacent to each other in our study area and they have different community compositions, structures, and dominant species. From mid spring and summer of 2016, sampling was down in a $1 \times 2 \mathrm{~m}$ plots within each habitat. In each habitat, in total 150 sampling plots were selected randomly with the constraint that it was at least $1 \mathrm{~m}$ from the margin to avoid edge effects. On the field, each plot was separated at least by $100 \mathrm{~m}$ from the others, to avoid spatial autocorrelation. We estimated the cover of each species per plot.

\section{Plant functional trait measurements}

We select the 44 most abundant species. Between four and 20 individuals per species were measured in sites. One well-developed entire leaf was collected per individual for trait measurement. The leaves were scanned and analyzed in the lab using the Leaf area matter software to measure their surface. We also measured the leaf dry mass after drying and weighting the leaves. The vegetation height $(\mathrm{VH}, \mathrm{m})$ was measured in the field as the distance between the top of the photosynthetic tissue and the ground. Specific leaf area (SLA; mm2 mg-1) was calculated as the ratio of the leaf surface to its dry mass. Seed mass (SM; mg) were compiled from seed databases (Goethe University Frankfurt, http://www.seeddispersal. info, and the Royal Botanic Gardens, http://data.kew.org/sid/). For the few species that we did not find seed mass values, we estimated the seed mass of each of these species from the average value of the species of the same genus that were registered (de la Riva et al. 2019), because seed mass is strongly conserved through the phylogeny (Lord et al. 1995). Given the multidimensionality of plant functions, we chose these three traits because of their importance in providing information about different independent axes of ecological strategies (see Díaz et al. 2016; Bruelheide et al. 2018). Specifically, we selected SLA, VH and SM as a subrogate of the plant strategies related with resource acquisition, competition for light and reproduction, respectively (Laughlin et al., 2010).

Soil collection and processing

Soil samples of the top $30 \mathrm{~cm}$ of depth (where nutrient uptake mostly occurs; Jobbágy and Jackson 2001) were collected from each sampling plot. Soil samples were randomly collected from three points using a bucket auger and mixed into a single soil sample and were brought into the laboratory in airtight plastic bags. All of the soil samples were air-dried and then filtered through a $0.2 \mathrm{~mm}$ sieve, discarding the visible roots and other plant debris. Soil $\mathrm{pH}$ was measured using a $\mathrm{pH}$ meter with a glass electrode (soil / $\mathrm{KCl}$ ratio is $1 \mathrm{~V} 2: 5$ ). Soil organic carbon was determined using the Walkley-Black method and a factor of 1.3 was applied to adjust the organic $C$ recovery (Nelson and Sommers, 1982). The soil available nitrogen, phosphorus and potassium were measured using the methods of Miller and Keeney (1982).

\section{Statistical analysis}

Following Garnier et al. (2004), the traits were weighted by the relative abundance of their constitutive species to calculate the community weighted mean (CWM) in each plot. The phylogenetic tree was 
obtained with the comprehensive Angiosperm species-level phylogeny from Zanne et al. (2014), as updated by Qian and Yin (2015), which is included in the R package 'S. PhyloMaker' (Qian and Yin.2015). The distance of the few species that were not found in the PhytoPhylo were supplanted by the distance of the closest species of the same genus found in the mega-phylogeny tree (de la Riva et al., 2019). For each plot we calculated the species richness (Pielou, 1969), represented by the total number of species per plot, the Faith's phylogenetic diversity index (PD), the functional richness (Frich) and the mean pairwise dissimilarity (MPD) index for both functional and phylogenetic diversity. PD was calculated with the R package 'PICANTE'; Kembel et al. (2010). To quantify the Frich index, we built a functional space through a Principal Coordinate Analysis (PCOA), using a Euclidean trait matrix after standardizing traits ( mean $=0, S D=1$ ) (Maire et al. 2015). We calculated the functional and phylogenetic MPD indices (FMPD and PMPD, respectively) based on existing algorithms (de Bello et al. 2016). These four indices integrate the main components of community structure enclosed by other related indices.

In order to account for trait coordination and to identify the major axes of trait variation, we run a Principal Component Analysis with the three CWM traits values (VH, SM and SLA) (Biotic_PCA). In addition, to reduce the number of variables characterizing the soil environment and their collinearity, other PCA was performed with the soil variables measured in this study (Soil_PCA). When necessary, variables were previously standardized and log-transformed to fulfil assumptions of normality (based on Kolmogorov-Smirnov) and homoscedasticity. We used an ANOVA analysis to check for differences on the distribution of the three types of habitats (Grassland, Shrubland, and Mixed) along the principal components analysis (PCA) in both biotic and soil PCAs. Post-hoc Tukey tests were performed to check the significance of differences between the least square means of each type of habitats. We also performed a one-way ANOVA to check for the variation of the diversity indices among habitats.

In order to evaluate shifts in the functional and phylogenetic structure distributions in response to edaphic factors, we used the generalized least-square model (GLS) controlling for the potential spatial correlation between soil variables associated with the type of habitat. We included a spatial autocorrelation structure using the cor-CAR1 function. We built one generalized least square regression model per community property; for each CWM trait and diversity index (respond variable) with the first and second Soil_PCA axes as predictors, using the gls function of the nlme package (Pinheiro et al. 2016). The variance explained by the GLS model was estimated by extracted the marginal $R^{2}$ value, which was calculated with the rsqueared function in the 'piecewise SEM' package (Lefcheck 2016).

In addition, we used null models to check if the functional and phylogenetic diversity patterns were a trivial consequence of species richness variation. We randomized the traits combinations across species, while fixing the number of species of each plot (999 runs) and estimating the same functional and phylogenetic indices. For each index, we estimated the Standardized Effect Size (SES, = (observed difference - mean null difference) / SD null differences), in order to assess if the relationship observed between the functional and phylogenetic indices and the soil variables were significantly different from those obtained between randomized communities (null differences). 
All the statistical analyses were performed using the R 3.1.3 software (R Development Core Team, 2014).

\section{Results}

Trait space distribution at community level was relatively well captured by the first two axes of the Biotic_PCA (Fig. 2). The first PCA axis accounted for $39.4 \%$ of overall variation and was related mostly with vegetation height. The second principal component, which explained $33.8 \%$ of the overall variance, was represented mainly by variations in SLA and SM. In addition, the first Soil_PCA axis (explaining $37.1 \%$ of the total variance) showed a high loading of soil nutrients $(\mathrm{N}, \mathrm{P}, \mathrm{K}, \mathrm{OM})$ and $\mathrm{pH}$, while the second axis (which explained $22.1 \%$ of the variance) exhibited a high loading of $\mathrm{pH}$ at the top and $\mathrm{K}$ at the bottom (Fig. 3). The positions of the plots along the first and second Soil_PCA axes reflect the segregation of the different types of habitats (Fig. 3 and Table 1), while not significant differences were found among habitats for the Biotic_PCA (data not shown). Thus, shrublands were significantly segregated from the other habitats, showing the highest nutrient concentration. In contrast, the grasslands show significantly the lowest nutrient concentration (Fig. 3 and Table 1). Significant differences were also observed in the second axis, where the mixed ecosystem was segregated by its higher values of $\mathrm{pH}$, while the shrubland was in the opposite end with higher values of $\mathrm{K}$.

The PCA of soil environmental factors showed a first main axis associated with soil fertility, while the second axis represent a trade-off between $\mathrm{pH}$ and soil $\mathrm{K}$, and both axes, from which plots segregate, were the most important factors associated with diversity variation (Fig. 4 and appendix S1). Also, Box plot show the variation of species richness and phylogenetic indices among habitats. The line inside the box represents the median value, the box limits are the 25th and 75th percentiles, error bars show 10th and 90th percentiles, and filled symbols show outliers. Different letters denote significant differences between habitats (Tukey's test).In this regard, the higher soil nutrient concentration (first Soil_PCA axis) and pH (second Soil_PCA axis) were significant and positive related with species and functional richness and Faith's phylogenetic distance, while not significant results were obtained for any functional trait at community level ( $\mathrm{SLA} \mathrm{C}_{\mathrm{CWM}}, \mathrm{VH}_{\mathrm{CWM}}$ and $\mathrm{SM}_{\mathrm{CWM}}$, data not shown) or for the functional and phylogenetic mean pairwise distance (appendix S1). Nevertheless, the results of this significant relationship were not consistent when applying the null model (SES). Therefore, the null model suggests that changes in functional richness and Faith's phylogenetic distance were the reflection of the variations in species richness (Appendix S2).

\section{Discussion}

Our results report several insights on the relationship between vegetation structure, soil nutrient concentration and land use in Damavand Mountain. The LHS strategy scheme assumes a certain degree of independence between these functional traits along three main dimensions (Westoby et al. 1998; Laughlin et al., 2010; Reich, 2014). Yet, our approach to this scheme focused on the community level does not uphold it. Our results show that trait distribution was relatively well capture by the first two axes of a principal component analysis (PCA) on which community trait values converge: one axis shows the 
positive covariation between SLA and plant height; while the positive covariation between SLA and seed mass could be loaded on separate axes. Surprisingly, community-level trait composition was poorly captured by the habitat or soil variables. This result suggests that species with opposing trait values coexist in the same habitat, which is unexpected. Similar results under different grazing regimes were obtained in arid environments (Vesk et al. 2004) or fertility gradients (Rusch et al. 2009), contrasting with others (Laliberté et al. 2012; Vaieretti et al. 2018). The discrepancy with our expectations could be due to the fact that we deliberately chose similar climatic conditions, to focus on grazing disturbance and soil nutrient availability. Arid conditions promote specific adaptations to the imposed climatic constraints, leading to relatively small differences in terms of functional syndromes (Reu et al. 2011; Bruelheide et al. 2018; de la Riva et al. 2018), and thus, despite some diversification of strategies exist (see Jacobsen et al. 2008), them are limited within the range of viable traits that allow plants to persist in this arid environment (de la Riva et al. 2016). Hence, aridity may limit the success of species that are not physiologically able to tolerate such water scarcity, reducing the range of functional traits. We acknowledge that our study is observational and, therefore, we cannot demonstrate if the results are a consequence of water deficit or of pre-existing patterns in the species assemblage, such as land use history. However, the fact that there were no different community trait syndromes among habitats, suggests that the climatic filtering act as dominant structuring processes of community trait composition, promoting strong trait convergence independently of the habitat (Gross et al., 2013; Bruelheide et al., 2018); while the local variation in environmental filters tends to alter species composition rather than functional composition, which has been previously observed in areas with relatively long disturbance history (Cingolani et al. 2005; Conti and Diaz. 2013).

Our results showed that soils from shrublands have higher nutrient concentration than grasslands. Trapping by livestock can lead to congestion and changes in levels of infiltration, bulk density and reduced destructive activities (Li et al., 2011 b; Yu and Jia, 2014). Moreover, under long-term pressure of grazing, some energy and nutrients are transmitted to the diet (Li et al., 2011b; Lu et al., 2015), while shrublands can collect a large amount of soil organic matter due to the increase of litter on the soil surface by the lowering of bed decomposition (Nieder and Benbi, 2008). This could be the consequence of the reduction segregation of the nutrient concentration among habitats. Overall, it seems that the phylogenetic and functional patterns responded more to the taxonomic richness variations than to traitbased assembly processes. These results are consistent with other studies in grazing areas where variations of functional diversity were related with species diversity (Niu et al. 2015; Simova et al., 2015; Salgado-Luarte et al., 2019). However, we observed an overall low covariation between species richness and functional and phylogenetic mean pairwise dissimilarity. This implies that the mechanisms that support the coexistence of the species not necessarily support the functional or phylogenetic differentiation among those species (de Bello et al., 2006), and thus, while aridity could more strongly constrain the overall functional and/or phylogenetic dissimilarity among species, competition for available resources could induce a niche differentiation among plants reaching the higher species richness in more productive plots (Turner 2008; Ceulemans et al. 2017). This pattern is especially 
common on resource-poor environment, where an in-creased availability of limiting resource may provide niche opportunities for coexisting plant species (Huston 1979, Willems et al. 1993; Turner 2008).

Overall, our research shows how some deterministic processes influenced functional and phylogenetic changes related with species richness in the semi-arid ecosystem from Damavand Mountain. However, the different traits and dimensions used show some correlations, and this, together with the lack of certain traits, which may be relevant to estimate a wide range of the functional niche occupation (e.g. belowground traits or leaf nutrients), could be limiting our assessments. Therefore, further studies based on meaningful syndromes or strategies should provide stronger tests of the underlying mechanisms causing community changes under different grazing regimes, which could be considerable importance in the effort to conserve taxonomic, functional and phylogenetic richness of these arid communities from west Asia.

\section{Conclusions}

In this study, we tried to discern the assemblage patterns of the semi-arid plant communities from Iran along natural nutrient gradient on three habitats. The functional and phylogenetic structures were mainly driven by soil nutrient availability, while the habitats, associated with three different grazing regimes, did not (apparently) exert any significant role. In fact, changes in the community functional and phylogenetic structure upon nutrient gradient can be explained by the variation of the species richness, while not differences were observed for the functional composition. Despite our observations also provide a significant understanding of the plant community assembly in these semi-arid communities from Damavand Mountain, long-term monitoring and higher number of functional dimensions are needed in future research. Our results show that the community-level trait composition was poorly captured by the habitat or soil variables. Soils from shrublands have higher nutrient concentration than grasslands, but this pattern has little effect over the functional or phylogenetic structure which tended to increase with nutrient content independently of grazing regimen. Also, suggest that the arid conditions of the region promote specific adaptations to the imposed climatic constraints, leading to relatively small differences in terms of functional syndromes, while the local variation in nutrient content tends to alter species composition rather than functional composition. Understanding the resistance of arid plant communities to global change is one of the most pressing issues to implement successful management measures. The results of this research can be used in major projects or implementation projects, because the functional and phylogenetic changes may help us to understand ecological processes, such as succession patterns and sustainability of communities. For instance, the species diversity and the soil characteristics seem to be a relevant driver of community structure and highlight the importance of considering the effects of ecological legacy on management plans. In this regard, favouring the expansion of shrubs patches on grasslands may promote communities with a higher nutrient concentration and species diversity, which could attenuate the potential impact of global change on these rangelands communities. 


\section{Declarations}

\section{Acknowledgement}

The corresponding author would like to express his sincere gratitude to the Faculty of Natural Resource, Agricultural of Sciences and Natural Resources University, Sari for providing the facilities to do this research during a research project.

\section{References}

1. Ashrafzadeh M, Erfanzadeh R (2014) Study on the effect of soil chemical characteristics and crown canopy of Ziziphus spina-christi L. on soil seed bank characteristics. J Range Water Manag 66(4): (477-491

2. Berdugo M, Kéfi S, Soliveres S, Maestre FT (2017) Plant spatial patterns identify alternative ecosystem multifunctionality states in global drylands. Nat ecol evol 1:0003

3. Bergholz K, May F, Giladi I, Ristow M, Ziv Y, Jeltsch F (2017) Environmental heterogeneity drives finescale species assembly and functional diversity of annual plants in a semi-arid environment.

Perspec in Plant Ecol. Evolut System 24:138-146

4. Bruelheide H, Dengler J, Purschke O, Lenoir J, Jiménez-Alfaro B, Hennekens SM, Kattge J (2018) Global trait-environment relationships of plant communities. Nature ecol evolu 2:1906

5. Cavender-Bares J, Kozak KH, Fine PVA, Kembel SW (2009) The merging of community ecology and phylogenetic biology. Ecol Lette 12(7):693-715

6. Ceulemans T, Bodé S, Bollyn J, Harpole S, Coorevits K, Peeters G, Honnay O (2017) Phosphorus resource partitioning shapes phosphorus acquisition and plant species abundance in grasslands. Nature plants 3(2):16224

7. Chang CC, HilleRisLambers J, Chang CC (2019) Trait and phylogenetic patterns reveal deterministic community assembly mechanisms on Mount St. Helens. Plant ecol 220:675-698

8. Cingolani AM, Posse G, Collantes MB (2005) Plant functional traits, herbivore selectivity and response to sheep grazing in Patagonian steppe grasslands. J Applied Ecol 42:50-59

9. Conti G, Díaz S (2013) Plant functional diversity and carbon storage-an empirical test in semi-arid forest ecosystems. J Ecol 101:18-28

10. De Bello F, Carmona CP, Lepš J, Szava-Kovats R, Pärtel M (2016) Functional diversity through the mean trait dissimilarity: Resolving shortcomings with existing paradigms and algorithms. Oecol 180:933-940

11. De Bello F, Lavorel S, Albert CH, Boulangeat I, Mazel F, Thuiller W (2013) Hierarchical effects of environmental filters on the functional structure of plant communities: a case study in the French Alps. Ecog 36:393-402

12. De Bello F, Lepš J, Sebastià MT (2006) Variations in species and functional plant diversity along climatic and grazing gradients. Ecog 29(6):801-810 
13. De la Riva EG, Godoy O, Castro Díez P, GutiérrezCánovas C, Vilà M (2019) Functional phylogenetic consequences of plant invasion for coastal native communities. J Vege Scie 30:510-520

14. De la Riva EG, Tosto A, PérezRamos IM: A plant economics spectrum in Mediterranean forests along environmental gradients: Is there coordination among leaf, stem and root traits? J Veg Sc. 27, 187199,2016

15. De la Riva EG, Violle C, PérezRamos IM, Marañón T, Navarro Fernández CM, Olmo M, Villar R,2018. A multidimensional functional trait approach reveals the imprint of environmental stress in Mediterranean woody communities. Ecosys, 21, 248-262

16. Delgado-Baquerizo M, Maestre FT, Gallardo A et al (2013) Decoupling of soil nutrient cycles as a function of aridity in global drylands. Nature 502(7473):672

17. Díaz S, Kattge J, Cornelissen JHC, Wright IJ, Lavorel S, Dray S, Gorné LD (2016) The global spectrum of plant form and fuction. Nature 529:167-171. https://doi.org/10.1038/nature16489

18. Eldridge DJ, Poore AG, RuizColmenero M, Letnic M, Soliveres S (2016) Ecosystem structure, function, and composition in rangelands are negatively affected by livestock grazing. Ecol Applica 26:12731283

19. Garnier E, Cortez J, Billes G, Navas ML, Roumet C, Debussche M, Laurent G, Blanchard A, Aubry D, Bellmann A, Neill C, Toussaint JP,2004.Plant functional markers capture ecosystem properties during secondary succession, Ecol, 85, 2630-2637

20. Golodets C, Sternberg M, Kigel J (2009) A community-level test of the leaf-height-seed ecology strategy scheme in relation to grazing conditions. J Veg Scie 20(3):392-402

21. Gross N, Börger L, SorianoMorales SI, Bagousse Pinguet $Y$ (2013) Uncovering multiscale effects of aridity and biotic interactions on the functional structure of Mediterranean shrublands. $\mathrm{J}$ Ecol 101:637-649

22. Huston MA (1979) A general hypothesis of species diversity. Am Nat 113:81-101

23. Jafarian Z, Kargar M, Tamartash R, Alavi SJ (2019) Spatial distribution modelling of plant functional diversity in the mountain rangeland, north of Iran. Ecol indicat 97:231-238

24. Jobbágy EG, Jackson RB (2001) The distribution of soil nutrients with depth: global patterns and the imprint of plants. Biogeoch 53:51-77

25. Jung V, Albert CH, Violle C, Kunstler G, Loucougaray G, Spiegelberger $T$ (2014) Intraspecific trait variability mediates the response of subalpine grassland communities to extreme drought events. $J$ Ecol 102:45-53

26. Keesstra SD, Bouma J, Wallinga J (2016) The significance of soils and soil science towards realization of the United Nations Sustainable Development Goals, SOIL 2: 111-128, doi:10.5194/soil2-111

27. Kembel SW, Cowan PD, Helmus MR, Cornwell WK, Morlon H, Ackerly DD, Webb CO (2010) Picante: R tools for integrating phylogenies and ecology. Bioinfor 26:1463-1464 
28. Laliberté E, Shipley B, Norton DA, Scott D (2012) Which plant traits determine abundance under longterm shifts in soil resource availability and grazing intensity? J Ecol 100(3):662-677

29. Laughlin DC, Leppert JJ, Moore MM, Sieg CH (2010) A multi trait test of the leaf-height-seed plant strategy scheme with 133 species from a pine forest flora. Functio Ecol 24:493-501

30. Lavorel S, Garnier E (2002) Predicting changes in community composition and ecosystem functioning from plant traits: revisiting the Holy Grail. Func Ecol 16:545-556

31. Lefcheck JS (2016) Piece wise SEM: Piecewise structural equation modelling in $r$ for ecology, evolution, and systematics. Meth in Ecol Evolu 7(5):573-579

32. LeónSánchez L, Nicolás E, Prieto I, Nortes P, Maestre FT, Querejeta JI (2020) Altered leaf elemental composition with climate change is linked to reductions in photosynthesis, growth and survival in a semi-arid shrubland. J Ecol 108:47-60

33. Li W, Huang HZ, Zhang ZN, Wu GL (2011) Effects of grazing on the soil properties and C and N storage in relation to biomass allocation in an alpine meadow, J. Soil Scie. Plant Nutri 11:27-39

34. Lord J, Westoby M, Leishman M (1995) Seed size and phylogeny in six temperate floras: Constraints, niche conservatism, and adaptation. Ameri Natur 146:349-364

35. Lu X, Yan Y, Sun J, Zhang X, Chen Y, Wang X, Cheng G (2015) Short-term grazing exclusion has no impact on soil properties and nutrients of degraded alpine grassland in Tibet, China. Solid Earth 6:1195-1205

36. Maire E, Grenouillet G, Brosse S, Villéger S (2015) How many dimensions are needed to accurately assess functional diversity? Global Ecolo. Biogeo 24:728-740

37. Miller RH, Keeney DR (1982) Methods of soil analysis, 2nd Edn. Part 2, Chemical and Microbiological Properties, ASA, SSSA, Madison, WI, 1-129

38. Nelson DW, Sommers LE (1982) Total carbon, organic carbon and organic matter, in: Methods of Soil Analysis, edited by: Page, A. L., Miller, R. H., and Keeney, D. R., Part 2, Chemical and Microbiological Properties Agronomy Monograph, 2nd Edn., American Society of Agronomy Inc., Madison,9:539-579

39. Nieder R, Benbi DK (2008) Carbon and Nitrogen in the Terrestrial Environment. Springer Science 159 $P$

40. Niu KC, He JS, Zhang ST, Lechowicz MJ (2015) Grazing increases functional richness but not functional divergence in Tibetan alpine meadow plant communities. Biodi Conser 25:2441-2452

41. Pérez-Ramos P, Manuel I, Delgado D, Ricardo Riva EG, de L, Montero, Francisco V, Teodoro L M (2017) Climate variability and community stability in Mediterranean shrublands: the role of functional diversity and soil environment. J Ecol 105:1335-1346. https://doi.org/10.1111/1365-2745.12747

42. Pérez-Ramos IM et al (2012) Evidence for a "plant community economics spectrum" driven by nutrient and water limitations in a Mediterranean rangeland of southern France. J Eco/ 100:13151327

43. Pielou EC (1969) An introduction to mathematical ecology. Wiley, New York 
44. Pinheiro J, Bates D, DebRoy S, Sarkar D (2016) R Core Team. nlme: linear and nonlinear mixed effects models. R package version 3.1-128. Bioinform 26:1463-1464

45. Qian H, Jin Y (2015) An updated megaphylogeny of plants, a tool for generating plant phylogenies and an analysis of phylogenetic community structure. J Plant Ecol 9:233-239

46. R Core Team R (2014) a language and environment for statistical computing. R Foundation for Statistical Computing, Vienna, Austria. URL http://www.R-project.org/

47. Reich PB (2014) The world-wide "fast-slow" plant economics spectrum: a traits manifesto. J Ecol 102:275-301

48. Reu B, Proulx R, Bohn K, Dyke JG, Kleidon A, Pavlick R, Schmidtlein S (2011) The role of climate and plant functional trade-offs in shaping global biome and biodiversity patterns. Global Ecol Bioge 20(4):570-581

49. Rusch GM, Skarpe C, Halley DJ (2009) Plant traits link hypothesis about resources and response to herbivory. Basic Appl Ecol 10:466-474

50. Salgado-Luarte C, Escobedo VM, Stotz GC, Rios RS, Arancio G, Gianoli E (2019) Goat grazing reduces diversity and leads to functional, taxonomic, and phylogenetic homogenization in an arid shrubland. Land Degr\& Develop 30(2):178-189

51. Sardans J, Rivas-Ubach A, Peñuelas J (2011) Factors affecting nutrient concentration and stoichiometry of forest trees in Catalonia (NE Spain). Forest Ecol Manag 262:2024-2034

52. Šímová I, Violle C, Kraft NJ, Storch D, Svenning JC, Boyle B, Piel WH (2015) Shifts in trait means and variances in North American tree assemblages: species richness patterns are loosely related to the functional space. Ecog 38(7):649-658

53. TanakaT, Sato T (2015) Taxonomic, phylogenetic and functional diversities of ferns and lycophytes along an elevational gradient depend on taxonomic scales. Plant ecol 216:1597-1609

54. Turner BJ (2008) Resource partitioning for soil phosphorus: a hypothesis. J Ecol 96:698-702

55. Vaieretti MV, lamamoto S, Harguindeguy NP, Cingolani AM: Livestock grazing affects microclimate conditions for decomposition process through changes in vegetation structure in mountain grasslands. Acta oecol 91: 101-107

56. Vesk PA, Leishman MR, Westoby M (2004) Simple traits do not predict grazing response in Australian dry shrublands and woodlands. J Appl Ecol 41:22-31

57. Westoby M: A leaf-height-seed (LHS) plant ecology strategy scheme. Plant and Soil 199: 213-227

58. Wieczynski DJ, Boyle B, Buzzard V, Duran SM, Henderson AN, Hulshof CM, Asner GP (2019) Climate shapes and shifts functional biodiversity in forests worldwide. Proceed Nati Acade Scie 116(2):587592

59. Willems JH, Peet RK, Bik L (1993). Changes in chalk-grassland structure and species richness resulting from selective nutrient additions. J. Veget science 4(2): 203-212. 1993

60. Wright IJ, Reich PB, Westoby M, Ackerly DD (2004) The worldwide leaf economics spectrum. Nature 428:821-827 
61. Xu J, Chen Y, Zhang L, Chai Y, Wang M, Guo Y, Yue M (2017) Using phylogeny and functional traits for assessing community assembly along environmental gradients: A deterministic process driven by elevation. Ecol Evol 7:5056-5069

62. Yang $Y$, Zhu Q, Peng $C$, Wang $H$, Chen $H$ (2015) From plant functional types to plant functional traits: A new paradigm in modelling global vegetation dynamics. Prog in Physic Geog 39(4):514- 535

63. Yu Y, Jia ZQ (2014) Changes in soil organic carbon and nitrogen capacities of Salix cheilophila Shneid along a revegetation Chrono sequence in semi-arid degraded sandy land of the Gonghe Basin, Tibet Plateau. Solid Ear 5:1045-1054

64. Zanne AE, Tank DC, Cornwell WK, Eastman JM, Smith SA, Royer DL (2014) Three keys to the radiation of angiosperms into freezing environments. Nature 506:89-92

\section{Tables}

Table 1.

Results of one-way ANOVA among habitats with the Soil PCA scores (see Fig. 3) for the three main axes. Abbreviations: Shr, Shrubland; Gra, Grassland; Mix, Mixed habitat.

\begin{tabular}{|lllll|}
\hline Response variable & Df & F & p & Post-hoc \\
\hline PC1 & 2 & 360.85 & $<0.001$ & Shr $>$ Mix $>$ Gra \\
\hline PC2 & 2 & 73.02 & $<0.001$ & Mix $>$ Gra $>$ Shr \\
\hline PC3 & 2 & 2.73 & 0.06 & \\
\hline
\end{tabular}

\section{Figures}




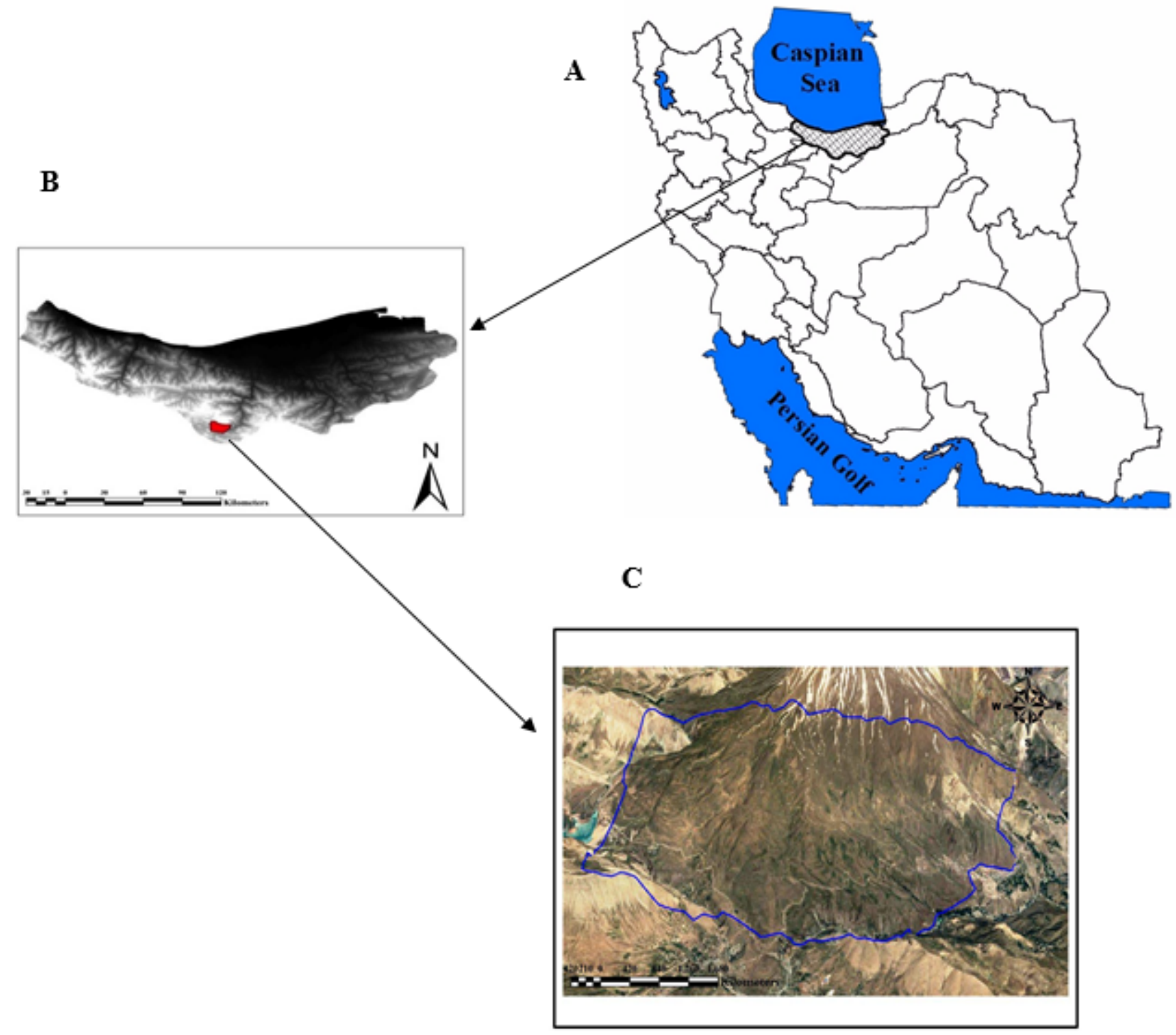

Figure 1

(A and B) The location of the study area in Iran and Mazandaran province, (C) The southern hillsides of Damavand Mountain of rangelands 


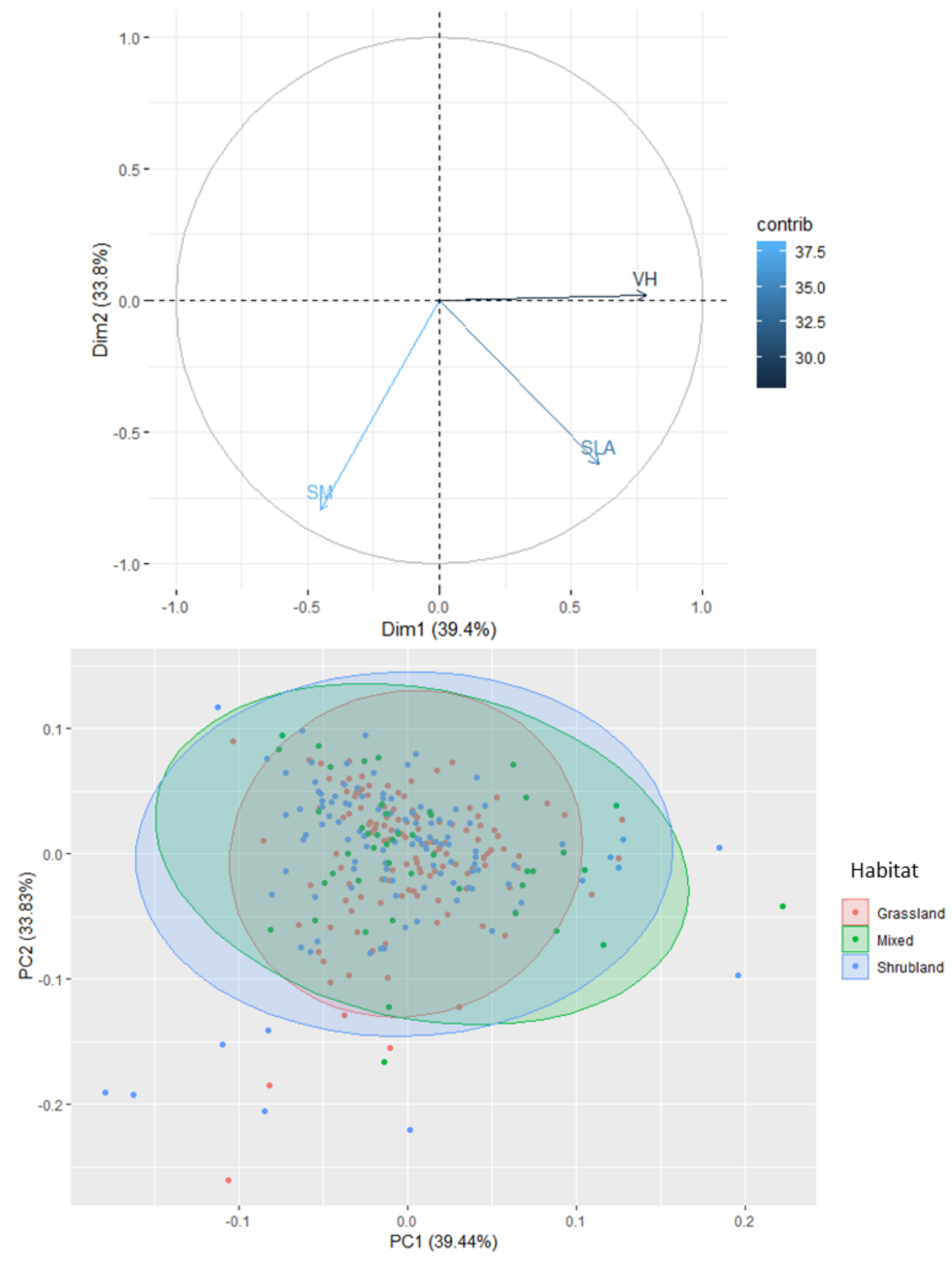

Figure 2

Principal components analysis (PCA) showing the trait distribution at community level (Community Weighted Means; CWM). 

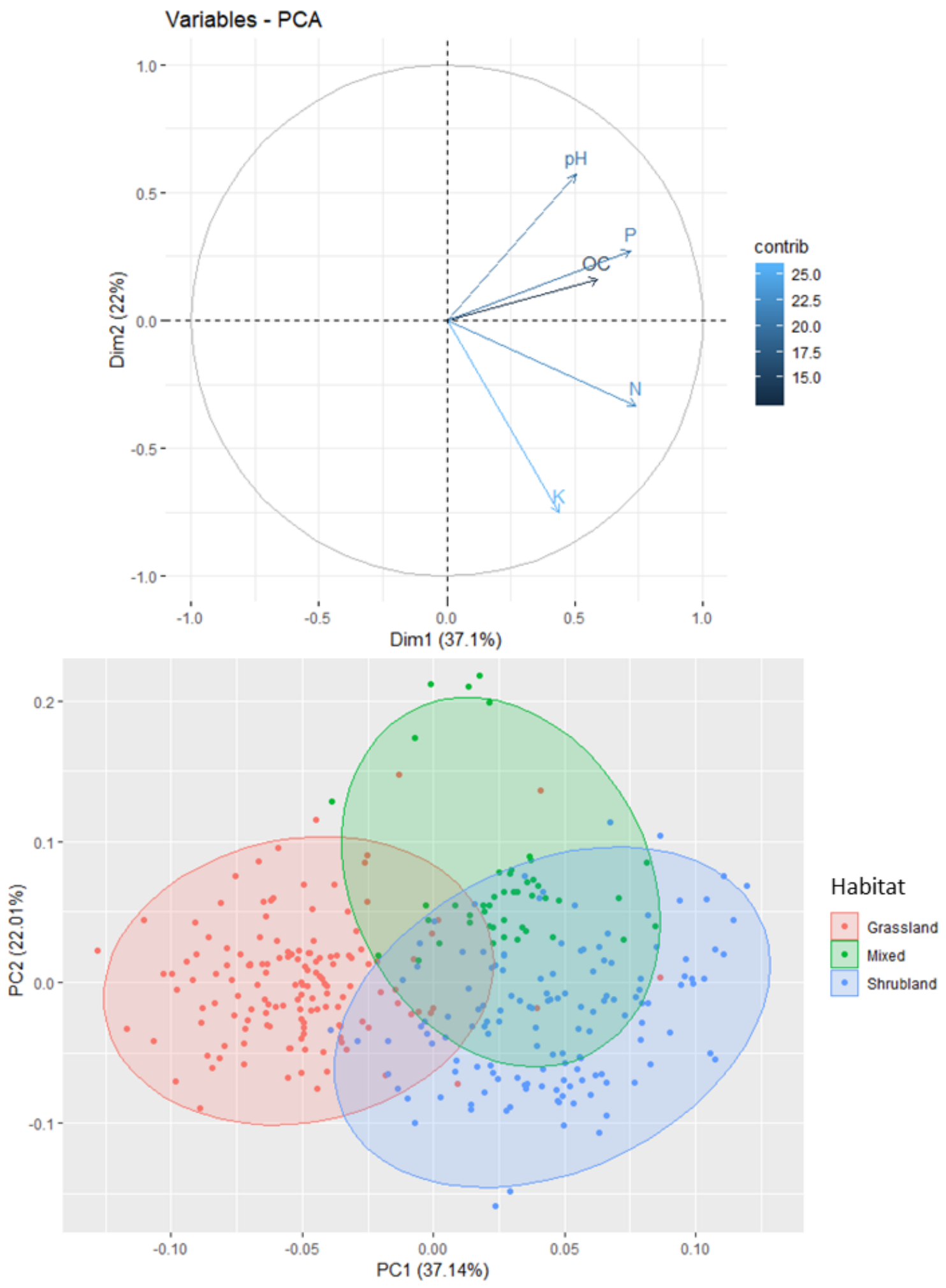

Figure 3

Principal components analysis (PCA) showing the soil variables per plot. 

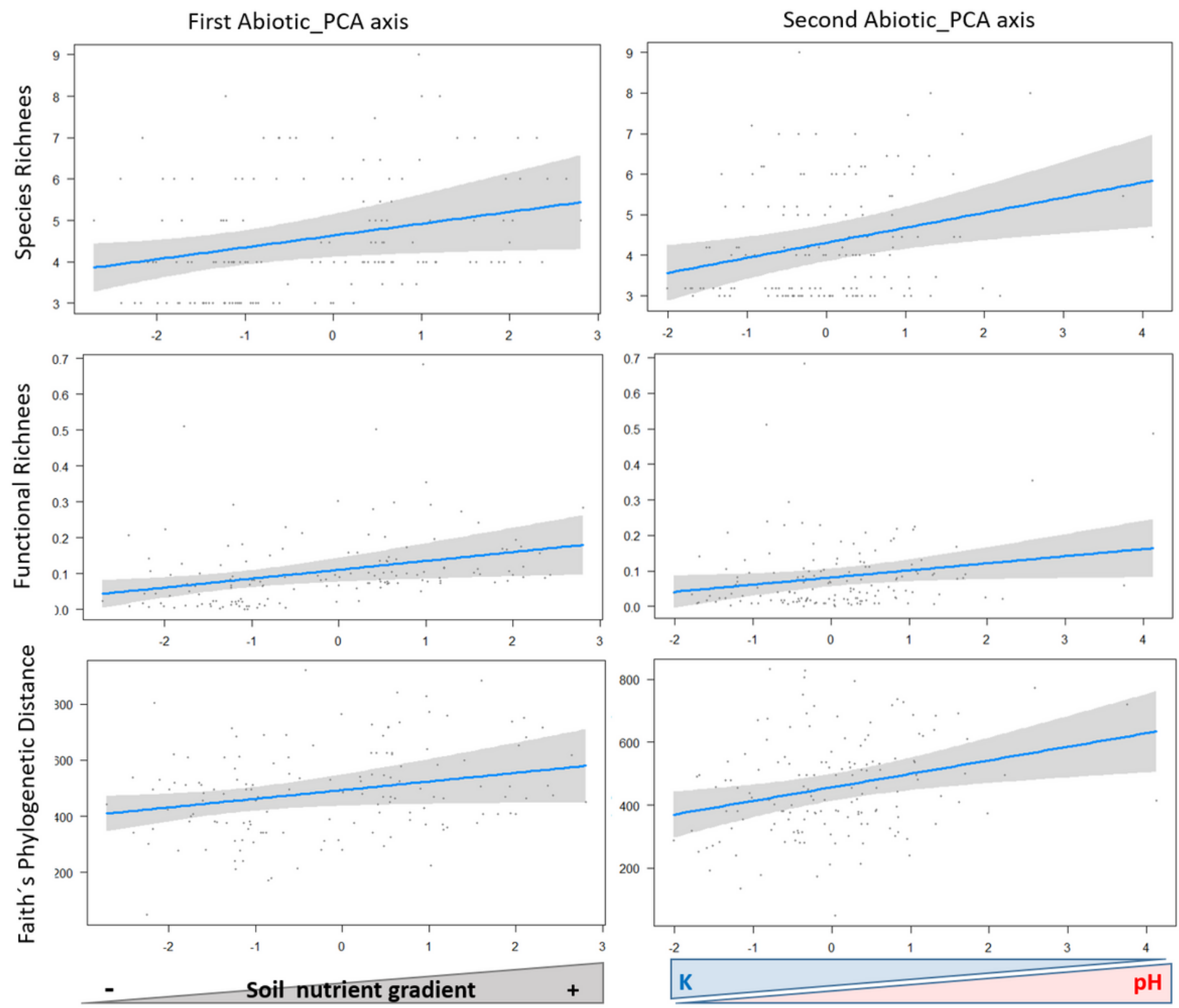

\section{Figure 4}

Relationship between the diversity indices at community level and the first and second PCA axes of the soil variables. The straight line corresponds to the estimated response of the diversity to soil variables by the GLS models. 


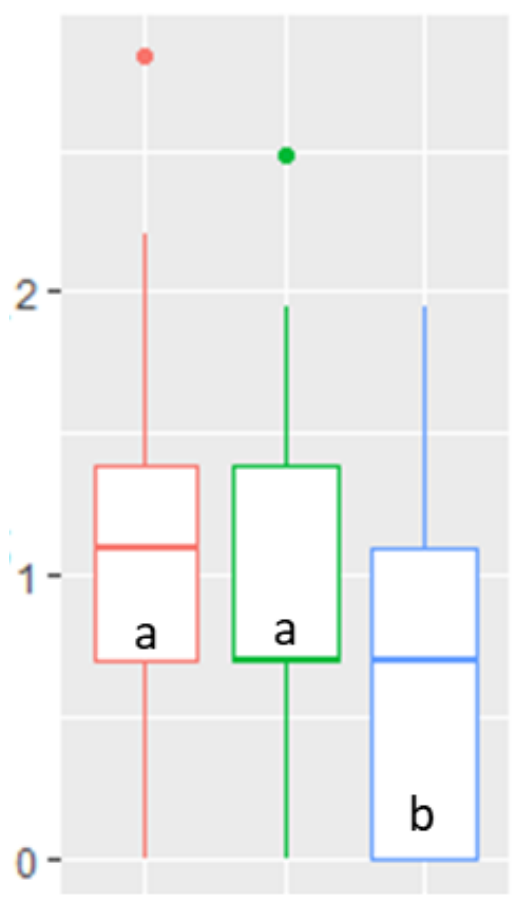

Species Richness

$(\log )$

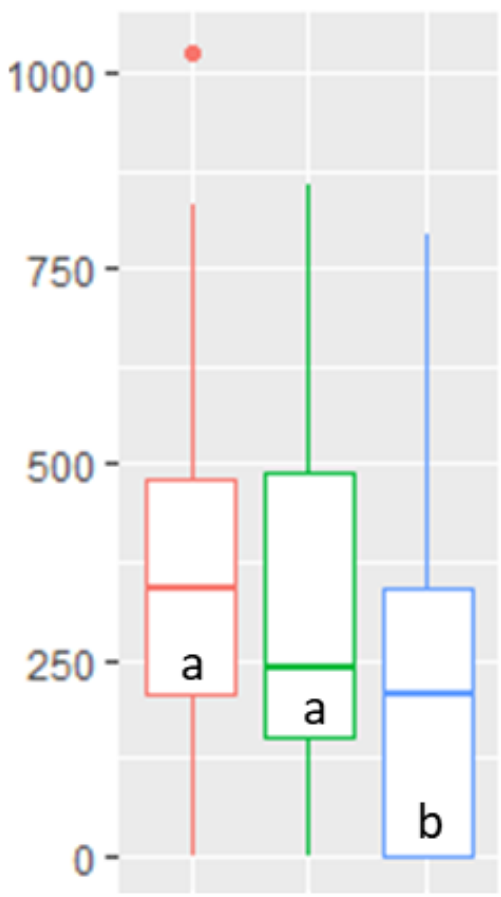

Faith's Phylogenetic Distance

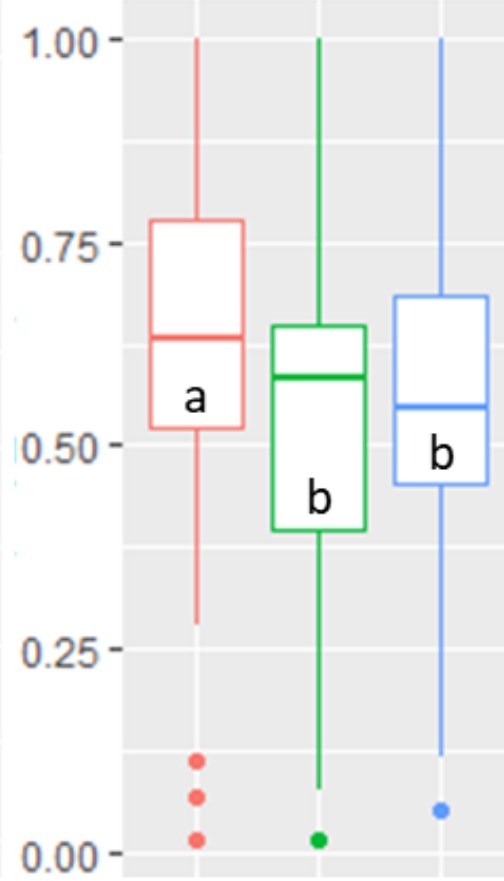

Habitat

Grassland

Mixed

Shrubland

\section{Figure 5}

Box plot show the variation of species richness and phylogenetic indices among habitats. The line inside the box represents the median value, the box limits are the 25th and 75th percentiles, error bars show 10th and 90th percentiles, and filled symbols show outliers. Different letters denote significant differences between habitats (Tukey's test).

\section{Supplementary Files}

This is a list of supplementary files associated with this preprint. Click to download.

- SupplementaryMaterial.docx 